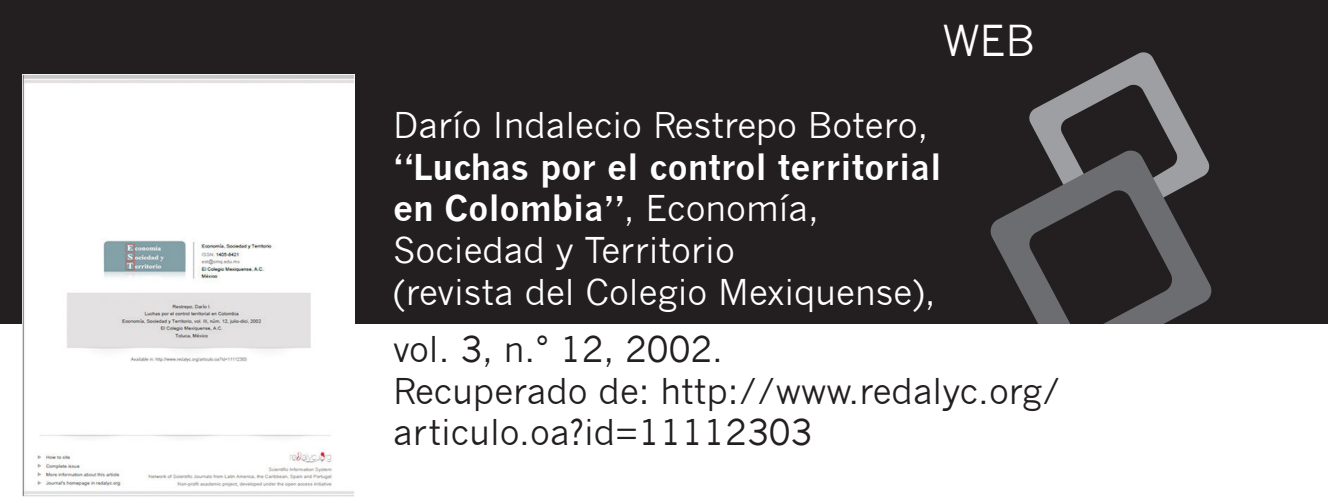

\title{
Luchas por el control territorial en Colombia
}

Este artículo es producto de una revisión y referenciación bibliográfica de diversos documentos, tales como investigaciones de tipo científico, artículos de revistas indexadas y documentos de carácter estatal. El autor es doctor en Historia de la Universidad Nacional de Colombia, con formación base de licenciatura en Filosofía, docente con amplia experiencia como investigador en las áreas sociales, económicas y de negocios.

La tesis central del artículo está orientada a la concurrencia entre los impactos de la globalización, el proceso de descentralización y la crisis política, que han debilitado el Estado, rompiendo las bases del centralismo político, administrativo y económico de Colombia. Plantea que existen luchas locales por la apropiación de las riquezas en las regiones y el control de las instituciones, lo cual genera la necesidad de negociación entre las fuerzas regionales y el Gobierno central, fundado respectivamente en las funciones descentralizadas regionalmente y las que mantiene el Gobierno de manera centralizada.

Este artículo ubica a la sociedad colombiana en un contexto de conflicto o de guerra política, planteando una eventual salida negociada al conflicto armado que se vive en varias regiones del país. Sostiene que esto traerá como consecuencia la redistribución del poder regional y nacional del país, requiriendo una nueva organización espacial del régimen político y electoral. El gasto público deberá tener una nueva redistribución, sustentado en la ineficacia del Estado actual para distribuirlo.

Las instituciones y los programas públicos no corresponden con el crecimiento y cantidad de población, la cual presenta la carencia de cobertura de los servicios básicos, lo que impide el avance de las regiones. El autor plantea que es necesario impulsar reformas a partir de tres principios: (1) que el Estado se comporte exactamente como el sector privado, el cual se supone eficiente; (2) que se privaticen el máximo de funciones y empresas estatales; y (3) que aquellas funciones y recursos que queden a cargo del Estado sean lo más permeables posible a las leyes del mercado. 
Lo anterior sugiere que existen intereses neoliberales en la descentralización, ya que esto facilita los procesos de privatización del Estado, como lo plantea el autor. Esto genera una competencia de los gobiernos locales por los recursos transferidos del nivel central, logrando una mayor eficiencia en los procesos administrativos, estimulando la distribución de recursos por la competencia, el mérito y el desempeño de unas entidades territoriales sobre otras.

La descentralización obliga a los gobiernos locales a emprender la privatización de las empresas y funciones del Estado, generando con ello que los servicios públicos domiciliarios, la salud y la educación, entre otros, pasen al sector privado del país y, en algunos casos, a multinacionales atendiendo al grado de rentabilidad que generan. Todos estos factores influyen en la guerra política que existe actualmente en las diferentes regiones del país.

El autor permite visualizar, con lo planteado en su análisis, desde el contexto social y económico del país, que los grandes consumidores de las políticas públicas descentralizadas, en materia de salud y educación, son las clases medias y los sectores populares. El neoliberalismo con la descentralización logra que las clases populares paguen más impuestos, mayores tarifas y participen en la ejecución de las obras, generando un ahorro al Estado y transfiriendo el costo de los bienes básicos a los consumidores.

Plantea que la descentralización promueve la competencia entre las empresas públicas y privadas, acabando con los monopolios estatales sobre la prestación de bienes y servicios, promueve la competencia entre empresas del Estado y del sector privado, generando con ello unos mayores niveles de eficacia en la prestación de los servicios a las comunidades.

Un buen aporte que hace el autor es que llega a la conclusión de que el Estado ha crecido en su gasto, instituciones, burocracia y programas, por encima de lo que la sociedad en su conjunto produce en ingresos para sostenerlo. Lo anterior ha generado que las empresas y los ciudadanos tengan que tributar en mayor cantidad, para poder sostener el Estado, aunado al mal manejo y distribución de los recursos, lo cual ha llevado a la no equitativa distribución o uso de los mismos.

De igual forma, plantea que el neoliberalismo tiene como estrategia presionar la conversión de los políticos en gerentes y administradores de los recursos públicos, llevando a que busquen una mayor eficiencia en la administración de los recursos, dejando a un lado los enfrentamientos ideológicos, a cambio de opciones éticas, morales y sociales. 


\section{WEB}

En el artículo se plantea que existen otros grupos -como son los grupos armados irregulares- que han influido en gran manera para que los gobiernos generen políticas de descentralización del Estado. Al menos el $40 \%$ del territorio nacional ha tenido influencia de algunos de estos grupos, ya sea guerrilla, paramilitarismo o narcotráfico. Lo anterior ha obligado a que, desde el nivel central, se lleven a estos territorios planes y programas que en cierta forma han influido en el crecimiento y desarrollo de las regiones.

En conclusión, se plantea por parte del autor que varios actores influyen en el proceso de descentralización del poder estatal, como son: las corrientes neoliberales, los nuevos movimientos sociales, el narcotráfico, la guerrilla y los paramilitares, quienes han influido en gran manera, por la apropiación y control de territorios.

Considero que la estructura, argumentación y presentación de conclusiones del artículo son muy pertinentes para el estudio del control territorial en Colombia, visto desde el contexto social.

Sinopsis a cargo de Mayor Germán Rafael Sierra Chaparro Decano de la Facultad de Estudios Policiales Especializados Dirección Nacional de Escuelas Policía Nacional de Colombia 